\title{
Fucosidases of Sperm and Milt in Darters (Percidae: Etheostomatini)
}

\author{
Jennifer J. Venditti* ${ }^{*}, 2$, Tamra C. Mendelson ${ }^{1,3}$ and Barry S. Bean ${ }^{1}$ \\ ${ }^{1}$ Lehigh University, Department of Biological Sciences, 111 Research Drive, Bethlehem, PA 18015, USA \\ ${ }^{2}$ Present Address: Department of Biology, Kutztown University, Kutztown, PA 19530, USA \\ ${ }^{3}$ Present Address: Department of Biological Sciences, University of Maryland Baltimore County, 1000 Hilltop Circle, \\ Baltimore, MD 21250, USA
}

\begin{abstract}
Darters (Percidae: Etheostomatini) offer attractive opportunities for analysis of the evolution of reproductive barriers and the molecular basis of fertilization. Here we report some basic characteristics of the sperm of darters, and, to our knowledge, the first report of sperm associated $\alpha$-L-fucosidase in fishes. Fluorometric enzyme assays using 4methylumbelliferyl-alpha-L-fucopyranoside [4-MU-fuc] as a substrate provided direct quantification of enzyme activity in both the soluble and cellular fractions of milt from all six species tested. Further analysis using SDS-PAGE and Western blotting revealed that fish sperm and milt contain $\alpha$-L-fucosidase isoforms with molecular weights similar to those reported for human semen. Fertilization of darter ova by conspecific sperm, as assessed by development of the embryo to the 4 cell stage, was inhibited by pretreatment of sperm with the fucosidase-specific competitive inhibitor DFJ, implicating the sperm fucosidase in fertilization and/or early embryogenesis. Identification of sperm associated $\alpha$-Lfucosidase in darters is consistent with the importance of carbohydrates during fertilization.
\end{abstract}

Keywords: Darter, etheostoma, percina, sperm, fucose, DFJ.

\section{INTRODUCTION}

Fertilization requires species-specific events involving recognition of both the sperm and egg components. Substantial evidence in the literature supports roles for carbohydrates during fertilization [1-10]. Research over the past two decades has led to the identification of sperm associated $\alpha$-L-fucosidases in humans [11-15] rats [16-18], Drosophila [19-21], ascidians [22], Unio elongatulus [23], chimpanzees [24], bulls [25] and Syrian hamsters (Venditti, Swann, and Bean, in revision), but not yet in fishes. Additionally, L-fucose has been shown to be important during fertilization [26-30]. Here we report an $\alpha$-Lfucosidase associated with darter sperm potentially involved during fertilization. This finding is provocative, as darters offer an attractive model system to evaluate further the functional role of $\alpha$-L-fucosidase and its potential relevance to the evolution of sperm-oocyte interactions.

Darters are freshwater, sexually dimorphic fish exhibiting external fertilization. The genus Etheostoma consists of 1617 subgenera with over 120 species and numerous additional subspecies and geographic races [31,32]. This genus, along with its sister genus Percina, constitute attractive subjects for analysis of the evolution of reproductive barriers and the cellular and molecular events of sperm-egg recognition and fusion. First, although breeding is seasonal, gametes can be easily obtained and sexes are readily distinguishable within species. The eggs are large in size, simplifying manipulation, and a transparent chorion allows development to be observed

*Address correspondence to this author at Lehigh University, Department of Biological Sciences, 111 Research Drive, Bethlehem, PA 18015, USA; Tel: 610-758-3678; Fax: 610-758-4004;

E-mail: jjv2@lehigh.edu easily. In addition, multiple species of darters may co-occur in a given habitat, making reproductive barriers of primary importance in maintaining species boundaries. For example, Mendelson et al. [33] demonstrated that sperm of Etheostoma hopkinsi will outcompete those of $E$. luteovinctum for fertilization of conspecific (same-species) eggs. Such conspecific sperm precedence represents a potentially important barrier to genetic exchange between species (e.g. [34]) and is likely to be mediated by speciesspecificity at the molecular level of gamete recognition.

Previous experiments investigating sperm competition and male behavior have been recorded for darters [35]; however no direct studies on sperm cells have been reported and little is known about the sperm of these fishes. In this paper, we examined sperm from six species of Etheostoma and Percina (tribe Etheostomatini), and we report the presence and functional activity of a sperm associated $\alpha$-Lfucosidase. Our studies using a specific inhibitor of $\alpha-\mathrm{L}-$ fucosidase provide evidence for a role of this spermassociated glycoprotein in fertilization or early embryo development in darters.

\section{MATERIALS AND METHODS}

\section{Specimens}

For these experiments fish were collected as follows: Etheostoma baileyi, four individuals from the Middle Fork of the Red River, Powell Co., KY; E. zonale, two individuals from the East Fork of the Barren River, Monroe Co., KY and two individuals from the Middle Fork of the Red River, Powell Co., KY; E. caeruleum, two individuals from the South Fork of the Little Barren River, Metcalfe Co., KY; E. bellum two individuals from the South Fork of the Little Barren River, Metcalfe Co., KY; E. coosae, two individuals 
from the Conasauga River, Polk Co., TN; and Percina nigrofasciata, one individual from Log Creek of the Savannah River, Edgefield Co., SC. For harvesting of milt, groups containing four individual males were sampled one time each, groups of two individuals were sampled twice on separate occasions, and the Percina individual was sampled four times on four separate occasions.

\section{Sperm Collection}

Sperm from each species was collected by gently squeezing males just dorsal to the genital pore. Males were anesthetized with $80 \mathrm{mg} / \mathrm{L} \mathrm{MS}-222$ (Sigma 5040), and milt was squeezed into an organ culture dish containing $200 \mu \mathrm{L}$ of Hank's buffer pre-diluted 1: 1 with sterile, distilled water ("half Hank's"). The milt was mixed to achieve uniform suspensions and used for subsequent enzyme assays. Live sperm were examined by brightfield, darkfield, and differential interference contrast microscopy. No evidence of microorganisms or nonsperm cells was found. Sperm concentrations (sperm $/ \mathrm{mL}$ ) and motility were determined microscopically using Cell-VU® counting chambers. Preparations like these, including some of those studied here, are fully capable of fertilizing fresh darter oocytes [33].

\section{in vitro Fertilization}

Fresh darter oocytes were obtained by gently squeezing gravid females anesthetized with $80 \mathrm{mg} / \mathrm{L}$ MS-222 (Sigma 5040 ) over a dry petri dish. Oocytes were inseminated with a $20 \mu \mathrm{L}$ droplet of conspecific sperm. Prior to insemination in some experiments, sperm were pre-treated with $1 \mu \mathrm{M}$ DFJ for 5 minutes. Microscopic evaluation of sperm pre-treated with DFJ revealed that treatment had no effect on sperm motility. Two minutes after insemination, the petri dish was inundated with aquarium water. Five minutes post inundation, the petri dish was placed into a tank on the aquarium system. Nonviable eggs (eggs that did not generate a single cell) were removed from the dish two hours after placement in the tank. Four hours after in vitro fertilization, oocytes were microscopically observed and the stage of division was recorded. If normal fertilization was achieved, eggs should be at the 4-cell stage. Additionally, treatment of uninseminated oocytes with $1 \mu \mathrm{M}$ DFJ did not inhibit the ability of oocytes to form a single cell. IVF dishes were observed using a Nikon SMZ 1500 dissecting microscope equipped with a Nikon DXM1200 digital camera.

\section{Microscopy}

Sperm were fixed in $2 \%$ paraformaldehyde solution for 10 minutes. Eight microliters of each sample was dried on an Esco Fluoro slide and mounted with $10 \mu \mathrm{L}$ Mowiol, and No. 1 coverslip. DIC images were obtained using a Zeiss LSM 510 Meta Confocal microscope with a $63 \mathrm{X}$ oil objective. Images were collected with polarized light from the Helium Neon 1 laser. Flagella and head measurements were acquired using LSM software version 3.2. Figures were assembled using Adobe Photoshop CS2.

\section{Immunolocalization of $\alpha$-Tubulin}

Ten microliters of E. caeruleum sperm collected in "half Hank's" was fixed as described above and dried onto Esco fluoro slides. Slides were washed with PBS and $30 \mu \mathrm{L}$ of primary, monoclonal mouse-anti- $\alpha$-tubulin clone B-5-1-2
IgG1 antibody (Sigma T6074) (1: 250) was added and incubated for 30 minutes in a moisture box at room temperature. Following primary incubation, slides were washed with PBS and incubated with $30 \mu \mathrm{L}$ of secondary goat-anti-mouse IgG Alexa 488 conjugated antibody (Molecular Probes A-11029) (1: 500) for 30 minutes in a moisture box at room temperature. Slides were washed 3 times with PBS followed by a final rinse with distilled water. To visualize nuclei, cells were labeled with $10 \mu \mathrm{M}$ propidium iodide (PI). Slides were mounted with $10 \mu \mathrm{L}$ of Mowiol followed by a No. 1 coverslip. Slides were examined and documented digitally using a Zeiss LSM 510 Meta confocal microscope. Figures were assembled using Adobe Photoshop CS2.

\section{Quantification of $\alpha$-L-Fucosidase Activity}

Enzyme activity in fish sperm and milt was measured as previously described [13], except volumes were scaled to a total of 60 microliters and no stop reagents were added. Fish sperm samples were not washed prior to enzyme assays due to fragility of the sperm cells. Enzymatic conversion of 4MU-fuc to the fluorescent product 4-methyl-umbelliferone (4MU) was monitored over 30 minutes, with individual measurements recorded at 10 minute intervals. For each species evaluated, relative $\alpha$-L-fucosidase activity was defined as the total [4-MU] nM after 30 minutes. Four independent enzyme assays were performed for each species, totaling 24 enzyme assays. Average total [4-MU] nM was calculated using the 30 minute time point value for each species from each of the four independent experiments. Standard error of the mean was calculated and graphically represented using error bars. Data were reported as average relative $\alpha$-L-fucosidase activity per species. Some experiments included a 5 minute pre-incubation, and inclusion in the final assay mixture, of either $1 \mathrm{mM}$ DFJ (deoxyfuconojirimycin) (Calbiochem) [36] or $50 \mu \mathrm{M}$ fucose, known competitive inhibitors of $\alpha$-L-fucosidase.

\section{SDS-Polyacrylamide Gel Electrophoresis (SDS-PAGE) and Western Blot Analysis}

SDS-PAGE was performed using a vertical gel apparatus (BioRad) with $5 \%$ stacking and $8 \%$ or $12 \%$ separating gels. Milt from E. caeruleum was collected in "half Hank's" and centrifuged 5 minutes, $6000 \mathrm{~g}$. Supernatant was removed and concentrated to half volume for 1 hour using an Eppendorf Vacufuge. To the pellet and supernatant, 75 microliters of protease inhibitor cocktail (Sigma P-2714) were added and the samples were stored at $-20^{\circ} \mathrm{C}$ overnight. Samples were thawed, diluted 1: 1 with pre-warmed $5 \mathrm{X}$ sample buffer, and boiled at $100^{\circ} \mathrm{C}$ for 5 minutes. $5 \mathrm{X}$ sample buffer contained $0.05 \%$ bromophenol blue, $5 \% \beta$-mercaptoethanol, 3\% SDS, and $62.5 \mathrm{mM}$ Tris $\mathrm{HCl}, \mathrm{pH} 6.8$.

Five microliters of BioRad low range protein standard or $15 \mu \mathrm{L}$ of each experimental sample were loaded and subjected to electrophoresis for 1 hour at $190 \mathrm{~V}$. After separation, proteins were electrotransferred onto $0.2 \mu \mathrm{m}$ nitrocellulose at $100 \mathrm{~V}$ for 1 hour. Membranes were exposed to $5 \%$ skim milk powder in PBST $(0.1 \%$ Tween) (Sigma P1379) for 1 hour to saturate nonspecific protein binding. Primary polyclonal goat-anti-human liver $\alpha$-L-fucosidase antibody was diluted 1: 1000 in 5\% milk and incubated with shaking at $4^{\circ} \mathrm{C}$ for 48 hours. Following incubation with 
primary antibody, the membrane was washed with PBST for 10 minutes. The membrane was then treated with secondary antibody, horseradish peroxidase (HRP) conjugated rabbitanti-goat-IgG (Zymed 81-1620) diluted 1: 2000 in 5\% milk, and incubated two hours at room temperature. The membrane was washed with PBST for 10 minutes and peroxidase activity was detected by chemiluminescence (Immun Star ECL) (BioRad 170-5041) by exposure of Kodak LS-X-Omat film.

\section{RESULTS}

Sperm from all species examined were morphologically similar and showed similar swimming. DIC images of sperm were collected from E. caeruleum and E. bellum (Fig. 1). The sperm had spherical heads with an average diameter of $2.8 \pm 0.1 \mu \mathrm{m}$. Staining with propidium iodide suggests the sperm contains little cytoplasm, as the whole head stains brightly red. Each intact sperm had a single, thin flagellum; flagellar length averaged $30.7 \pm 1.0 \mu \mathrm{m}$. Flagella contain axonemal structures composed of microtubules, which are filaments composed of tubulin subunits. Immunolocalization of $\alpha$-tubulin showed localization along the length of the flagellum, as expected for axonemal microtubule staining (Fig. 2). Placing sperm in solutions with osmolarity greater than $160 \mathrm{mOsm}$ or water caused flagella to curl upon the head within $3 \mathrm{~min}$, followed by rapid loss of motility. Motility was unaffected by the addition of either $1 \mathrm{mM}$ deoxyfuconojirimycin (DFJ) or $50 \mu \mathrm{M}$ L-fucose. Sperm remained motile for up to 1 hour post collection in "half Hank's" buffer, and were able to fertilize fresh darter oocytes for at least 30 minutes post collection.

Analysis of $\alpha$-L-fucosidase enzyme activity using fluorometry revealed that $\alpha$-L-fucosidase was present in all six species tested. The average relative $\alpha$-L-fucosidase activity values for each species are presented in Fig. (3). Additionally, $96 \%$ and $95 \%$ of the sperm associated $\alpha-\mathrm{L}-$ fucosidase activity was inhibited by the addition of either 50 $\mu \mathrm{M}$ L-fucose or $1 \mathrm{mM}$ DFJ, respectively, 5 minutes prior to enzyme assays. Enzyme activity was inhibitable in all experiments by these known competitors, confirming that the generation of $4 \mathrm{MU}$ in the assay mix is due to $\alpha$-L-fucosidase activity. Assays omitting sperm or 4-MU-fuc had no measurable enzyme activity. The variation observed in $\alpha$-Lfucosidase activity across samples within each species is expected. Semen production in mammals is not homeostatically regulated such that no two semen samples are identical. For human semen, samples from the same donor can be very different. In these experiments, sperm was collected on separate occasions and collection parameters (i.e. force of squeezing, volume of sample) were kept as uniform as possible from specimen to specimen. It is possible that seasonal reproductive changes, protein content, $\mathrm{pH}$, and/or contamination by scale tissue could explain the variation of $\alpha$-L-fucosidase within or between species.

Preliminary partitioning experiments were performed to evaluate the association of $\alpha$-L-fucosidase with the sperm cell versus the liquid fraction of milt following high speed centrifugation. Quantification of enzyme activity following centrifugation at $10,000 \mathrm{~g}$ or $6000 \mathrm{~g}$ revealed that $70 \%$ of the $\alpha$-L-fucosidase activity was detectable in the supernatant and $30 \%$ was detectable in the cell pellet. These results suggest $\alpha$-L-fucosidase is associated with the fish sperm cell. The $\alpha$ L-fucosidase activity detected in the supernatant could be an isoform associated with the liquid portion of milt, or enzyme that was released from the sperm cell following manipulation by centrifugation.

Western blot analysis of milt from E. caeruleum showed the presence of $\alpha$-L-fucosidase isoforms with molecular weights similar to those of human liver $\alpha$-L-fucosidase (Fig. 4). Purified human liver $\alpha$-L-fucosidase was loaded in lane 1 , and two intense bands were present. These bands correspond to the two subunits of human liver $\alpha$-L-fucosidase reported to be $51 \mathrm{kDa}$ and $56 \mathrm{kDa}$ in size [37]. The sperm cell pellet isolated from E. caeruleum sample was loaded in lane 2. Three major and two minor bands were present on the blot. Two of the bands present correspond to the $51 \mathrm{kDa}$ and 56 $\mathrm{kDa}$ bands of human liver $\alpha$-L-fucosidase. One band with a molecular weight larger than $56 \mathrm{kDa}$ and two minor bands with molecular weights lower than $51 \mathrm{kDa}$ were also present.
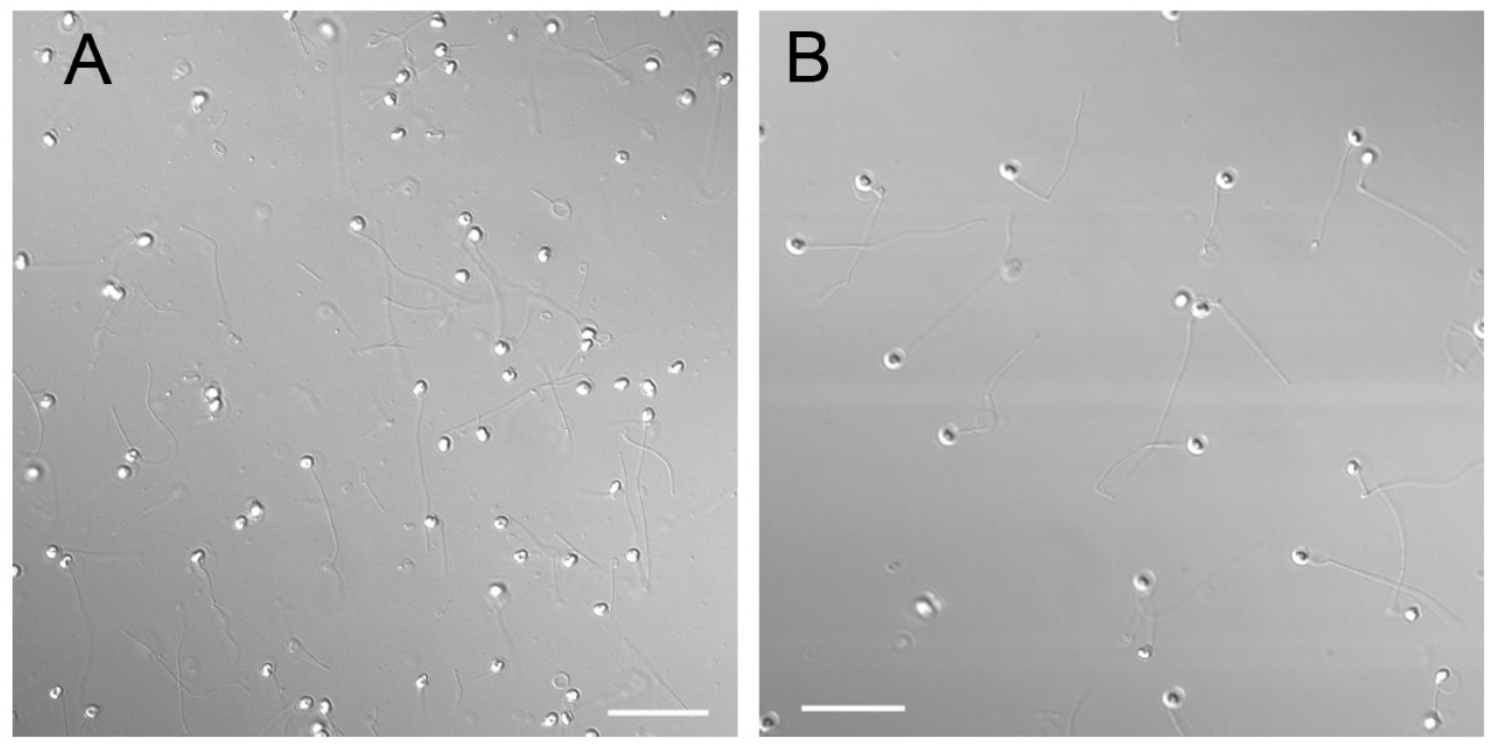

Fig. (1). Differential interference contrast (DIC) images of E. caeruleum (A) and E. bellum (B) sperm. Scale bar equals $20 \mu \mathrm{m}$. 
The larger molecular weight band could represent multiple $\alpha$-L-fucosidase subunits interacting. The lower molecular weight bands could represent 1) unique subunits or isoforms of $\alpha$-L-fucosidase only found in darters or 2) degradation products of $\alpha$-L-fucosidase subunits. Lane 3 contained supernatant isolated from an E. caeruleum sample following high speed centrifugation. This lane contained two major bands corresponding in molecular weight to the 2 bands in lane 1 . The dark smears in lanes 2 and 3 could be due to the presence of lipids in the gel samples, as lipid aggregates run along the sides of the lanes. Both the sperm and milt fractions of E. caeruleum show at least two bands sharing the same molecular weight as those reported for human liver $\alpha$-L-fucosidase, confirming the presence of the enzyme in both the sperm cell and fluid.

In vitro fertilization experiments were performed to evaluate the potential role of $\alpha$-L-fucosidase during fertilization. Multiple fertilization conditions were examined, and all trials showed a decrease in fertilization success when sperm, or oocytes, were pre-treated with DFJ prior to insemination. Data from two IVF experiments showing the strongest inhibition are shown in Table 1. In these instances, pre-treatment of sperm with $1 \mu \mathrm{M}$ DFJ for 5 minutes prior to insemination yielded a 5.1 and 13.3 fold reduction in fertilization success, respectively, compared to the untreated, control experiments. Representative images from one fertilization experiment are shown in Fig. (5). The sham condition (Fig. 5A) shows oocytes pre-treated with $1 \mathrm{mM}$ DFJ for 5 minutes prior to inundation. All oocytes formed a single cell, indicating that DFJ does not affect the viability of darter oocytes. By four hours post insemination, oocytes inseminated with untreated sperm had developed to the 4cell stage (Fig. 5B). Alternatively, the majority of oocytes inseminated with sperm pre-treated with $1 \mathrm{mM}$ DFJ for 5 minutes did not divide and remained at the 1-cell stage (Fig. 5C).

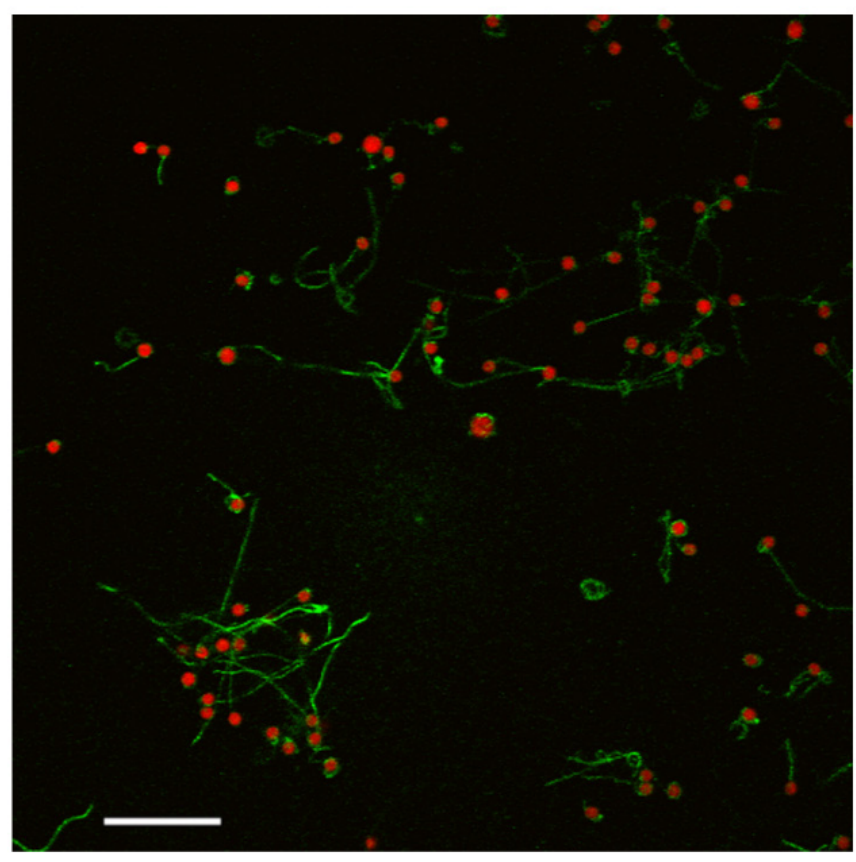

Fig. (2). Confocal micrograph of E. caeruleum sperm showing tubulin (green) in the sperm tails and DNA (red) in the nuclei. Tubulin was labeled with anti-tubulin antibodies and nuclei were labeled with propidium iodide. Scale bar equals $20 \mu \mathrm{m}$.

\section{DISCUSSION}

Early work defining the morphological characteristics of fish sperm [38, 39] established the foundation for an area of research that continues to grow. Since these early studies, morphological features and ultrastructural details have been reported for many fish species. Identification of these sperm characteristics is important, as they may have evolutionary significance, particularly with respect to the evolution of sperm-oocyte recognition within and between species. The

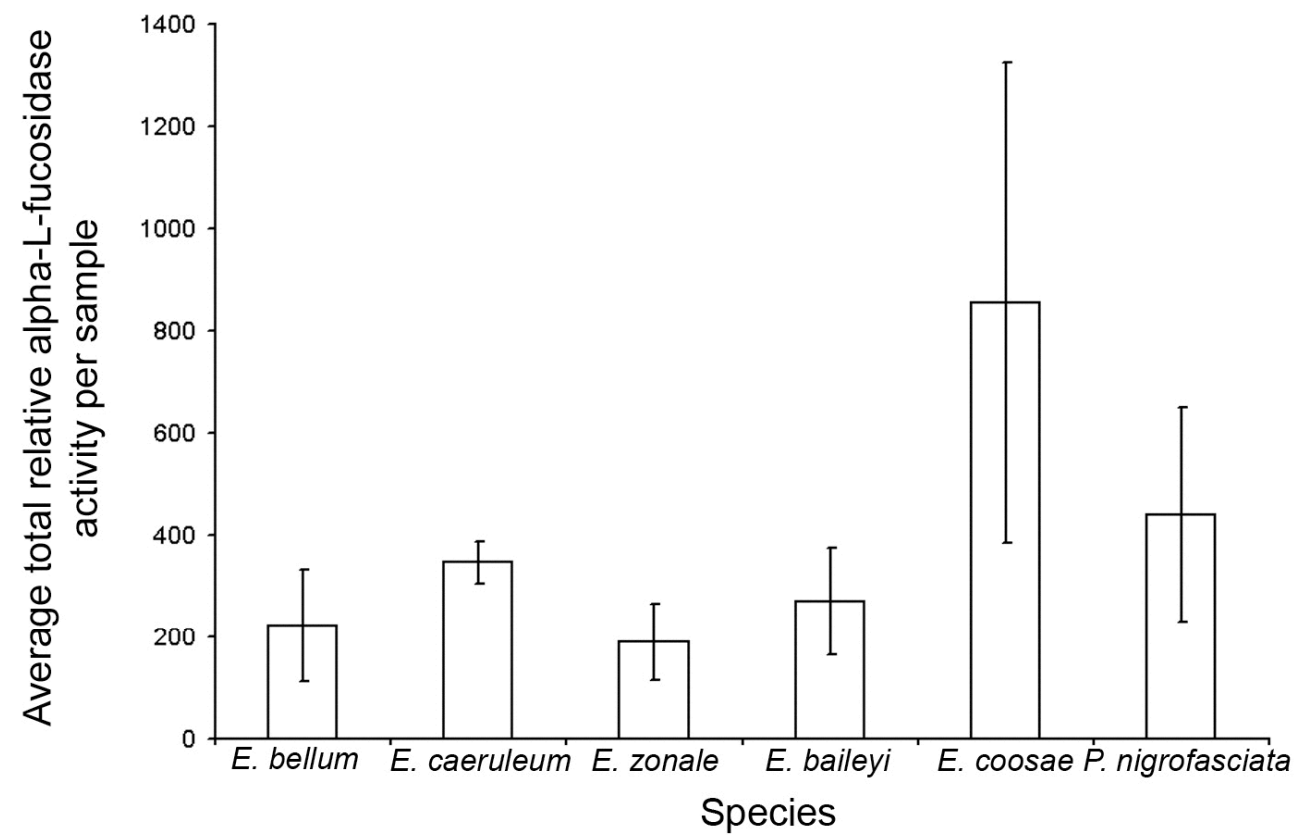

Fig. (3). Average total alpha-L-fucosidase activity per sperm sample for each species evaluated. Average enzyme activity calculated from four independent experiments. Error bars represent standard error of the mean. 
morphological characteristics of darter sperm reported here share similarities with spermatozoa of other fish. Teleost sperm have been reported to have round heads $1.5-2.0 \mu \mathrm{m}$ in diameter [40]. Cichla intermedia spermatozoa heads are also round, $1.8 \mu \mathrm{m}$ in diameter, with a narrow strip of cytoplasm [41]. Some Sciaenidae species have been reported to possess spherical heads [42]; finally, spermatozoa of Pandora, Pagellus erythrinus L., and cardinal fish also have single, thin flagella [43, 44].

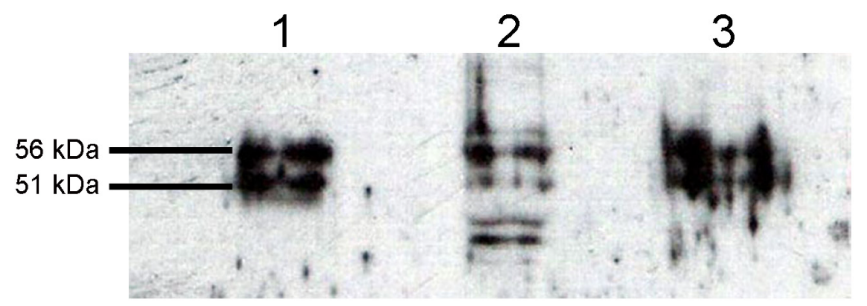

Fig. (4). Western blot analysis of sperm and supernatant fractions isolated from E. caeruleum. Sample lanes contained purified human liver alpha-L-fucosidase (1), E. caeruleum sperm pellet (2), and $E$. caeruleum sperm pellet supernatant fraction (3). The bands in lane 1 are reported to be $56 \mathrm{kDa}$ and $51 \mathrm{kDa}$ in size.

Fucosidases are widespread or ubiquitous among organisms, and seem essential for basic biochemical (housekeeping) functions [37, 45]. In this report we present several lines of evidence that fucosidase is present in the sperm of these fishes: we a) demonstrated fucosidase enzyme activity in milt, $b$ ) found that a good fraction of that activity travels with the sperm cells during centrifugation, c) confirmed it's reactivity to polyclonal antibody raised against human liver fucosidase, d) determined that its banding in gel electrophoresis resembles that seen in other vertebrates, and e) demonstrated its sensitivity to inhibition by the high affinity competitive and specific fucosidase inhibitor DFJ. These enzymes occur with two or three primary structural variants in many species, each of which show considerable conservation in both their protein and DNA sequences [45]. Two genes for fucosidases have been previously reported for the zebrafish Danio rerio [45]. The characteristics of darter fucosidase isoforms reported here resemble those of other vertebrates [45] with regard to glycoprotein size and their cross-reactivity to antibody against human liver $\alpha-\mathrm{L}-$ fucosidase. In addition to the expected, general cellular housekeeping functions of fucosidase, it's prominence in milt and sperm cells adds to the growing evidence for roles in reproduction.

Sperm associated $\alpha$-L-fucosidases have been reported in several other organisms and are considered to be strong candidates for important roles during fertilization $[11,12$,
$16,18-22]$. This report describes a sperm associated $\alpha$-Lfucosidase in darters, suggesting that fish too may require $\alpha$ L-fucosidase for fertilization. Indeed, preliminary in vitro fertilization (IVF) experiments suggest $\alpha$-L-fucosidase may be involved during fertilization in darters. Oocytes were collected from gravid darters and inseminated with freshly collected conspecific sperm. Four hours post insemination, oocytes were microscopically evaluated for development to the 4-cell stage and fertilization success was recorded. For some experiments, prior to insemination, sperm were pretreated with DFJ, a known and specific competitor $\alpha$-Lfucosidase. Treatment of sperm with DFJ decreased fertilization success in some trials, suggesting $\alpha$-Lfucosidase was involved during fertilization. For some IVF experiments, however, pre-treatment of sperm with DFJ had no effect on fertilization success compared to the control experiment. Sperm concentrations were not standardized or optimized in these experiments, so despite pre-treatment of sperm with DFJ, oocytes overwhelmed with sperm may still have been fertilized. Additional experiments are needed to strengthen this finding; however, preliminary data are consistent with our current understanding of carbohydrates and their roles during fertilization.

The evolutionary relevance of fucosidases has been explored recently by Intra et al. [45], who have documented widespread phylogenetic conservation of the structure of the genes that specify the alpha-L-fucosidases. While there is considerable conservation in amino acid structure, most of these structures still include several different residues that can be glycosylated, and numerous intermediate and final isoforms of fucosidase glycoproteins have been reported [12, 37]. The fucosidases are widely distributed acid hydrolases with lysosomal catabolic functions that are essential for the degradation of polysaccharides and the polysaccharide components of glycolipids and glycoproteins [37]. In humans, homozygosity for FUCA1 deficiency results in fucosidosis, which is lethal to children [46]. This fundamental role in cellular housekeeping seems the likely explanation for the phylogenetic conservation of fucosidase gene and protein structures.

However, several recent reports have identified isoforms of fucosidase in the male reproductive system that function well in the neutral $\mathrm{pH}$ range and include isoforms that are associated with the membrane system of sperm cells [11-15, 17, 19]. As outlined in the introduction, there is abundant evidence to implicate biochemical recognition of fucose residues in the reproduction of many species. These functions may include direct roles in sperm-oocyte recognition and binding, and the arrival of sperm-associated

Table 1. Fertilization success is reduced by pre-treatment of sperm with DFJ prior to insemination. Data from two independent in vitro fertilization experiments using gametes from $E$. coosae and $E$. baileyi. Oocyte clutches were inseminated with a $20 \mu \mathrm{L}$ droplet of conspecific sperm. Oocytes were microscopically observed for development to the 4-cell stage

\begin{tabular}{|c|c|c|c|c|c|c|}
\hline Experiment \# & Sperm Treatment & \# Viable Eggs & \# Fertilized Eggs & \# Sperm/Droplet & Fertilization Success & Species \\
\hline \hline 1 & untreated & 47 & 36 & 680,000 & $81 \%$ & E. coosae \\
\hline 1 & $1 \mu \mathrm{M}$ DFJ, 5 min. & 37 & 6 & 840,000 & $16 \%$ & E. coosae \\
\hline 2 & untreated & 25 & 10 & 540,000 & $40 \%$ & E. baileyi \\
\hline 2 & $1 \mu \mathrm{M}$ DFJ, 5 min. & 34 & 1 & $1,300,000$ & $3 \%$ & E. baileyi \\
\hline
\end{tabular}




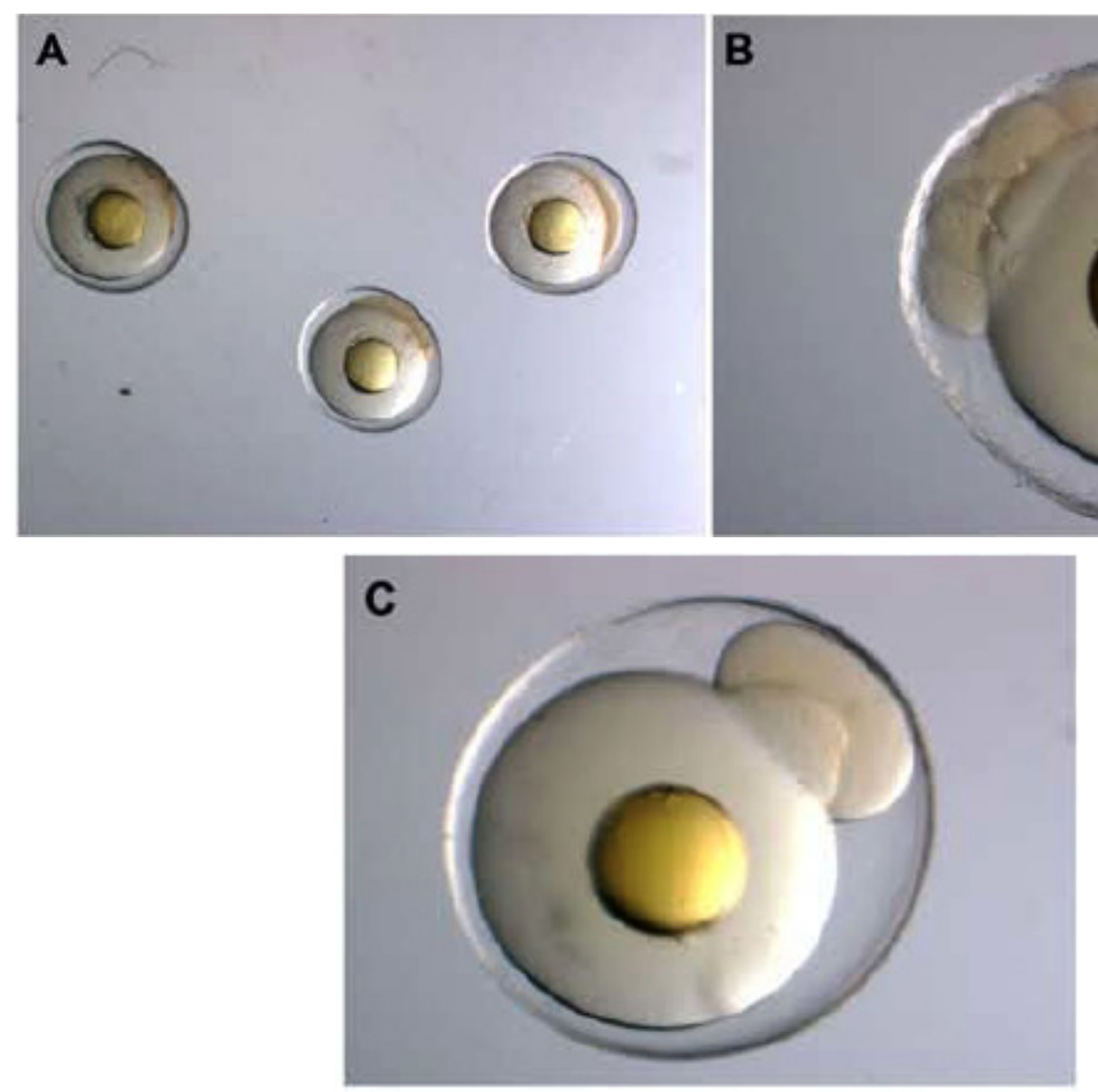

Fig. (5). E. flavum oocytes from in vitro fertilization experiments. Un-inseminated oocytes (A) exposed to $1 \mathrm{mM}$ DFJ showed formation of a single cell, indicating DFJ does not effect oocyte viability. Oocytes inseminated with untreated sperm (B) showed development to the 4-cell stage. Oocytes inseminated with DFJ pre-treated sperm (C) remained at the single cell stage.

fucosidase in the otherwise fucosidase-deficient ooplasm may serve as an important regulatory trigger for further embryonic development $[14,15]$. Herein we have reported the presence of sperm-associated fucosidase in fishes. AlphaL-fucosidase enzyme activity is present in both the seminal fluid and the sperm cells themselves, with a significant proportion remaining in the tiny volume that forms the cellular pellet following centrifugation at 6,000 or $10,000 \mathrm{xG}$. Among the six species examined, the relative amount of fucosidase activity differed. Our preliminary results suggest that, at appropriate concentrations of fucosidase inhibitor, fertilization is inhibited. This evidence supports our hypothesis that the fucosidase has a direct role in the fertility of these fishes.

We hope that future investigations will address the unresolved questions of the roles of fucosidases for withinand across-species gamete recognition and fertilization in fishes. The possibility remains that variation in fucosidase isoforms and fucose-containing sperm receptor structures could be a focus for development of species barriers and speciation.

\section{ACKNOWLEDGEMENTS}

The authors would like to thank Dr. Jack Alhadeff for anti-fucosidase antibodies, Dr. Lynne Cassimeris for providing anti-tubulin immunolocalization reagents, and Anna Gumpert and Vance Imhoff for technical assistance.

\section{REFERENCES}

[1] DeMott RP, Lefebvre R, Suarez SS. Carbohydrates mediate the adherence of hamster sperm to oviductal epithelium. Biol Reprod 1995; 52(6): 1395-403.

[2] Lefebvre R, Lo MC, Suarez SS. Bovine sperm binding to oviductal epithelium involves fucose recognition. Biol Reprod 1997; 56(5): 1198-204.

[3] Lefebvre R, Lo MC, Suarez SS, Scamper JC. Specific inhibition of equine sperm binding to oviductual epithelium. Equine Reprod VI 1995; 1: 689-96.

[4] Suarez SS, Revah I, Lo M, Kolle S. Bull sperm binding to oviductal epithelium is mediated by a $\mathrm{Ca}^{2+}$-dependent lectin on sperm that recognizes Lewis-a trisaccharide. Biol Reprod 1998; 59(1): 39-44.

[5] Tulsiani DR, Yoshida-Komiya H, Araki Y. Mammalian fertilization: a carbohydrate-mediated event. Biol Reprod 1997; 57(3): 487-94.

[6] Wassarman PM. Mouse gamete adhesion molecules. Biol Reprod 1992; 46(2): 186-91.

[7] Whyte A, Allen WR. Equine endometrium at pre-implantation stages of pregnancy has specific glycosylated regions. Placenta 1985; 6(6): 537-42.

[8] Lee MC, Wu TC, Wan YJ, Damjanov I. Pregnancy-related changes in the mouse oviduct and uterus revealed by differential binding of fluoresceinated lectins. Histochemistry 1983; 79(3): 365-75.

[9] Benoff S. Carbohydrates and fertilization: an overview. Mol Hum Reprod 1997; 3(7): 599-637.

[10] Shalgi R, Raz T. The role of carbohydrate residues in mammalian fertilization. Histol Histopathol 1997; 12(3): 813-22.

[11] Khunsook S, Alhadeff JA, Bean BS. Purification and characterization of human seminal plasma alpha-L-fucosidase. Mol Hum Reprod 2002; 8(3): 221-7. 
[12] Khunsook S, Bean BS, McGowan SR, Alhadeff JA. Purification and characterization of plasma membrane-associated human sperm alpha-L-fucosidase. Biol Reprod 2003; 68(3): 709-16.

[13] Alhadeff JA, Khunsook S, Choowongkomon $\mathrm{K}$, et al. Characterization of human semen alpha-L-fucosidases. Mol Hum Reprod 1999; 5(9): 809-15.

[14] Venditti JJ, Bean BS. Stabilization of membrane-associated alpha1-fucosidase by the human sperm equatorial segment Int J Androl 2008 [Epub ahead of print]. Doi: 10.1111/j.1365-2605.2008.00897.

[15] Venditti JJ, Donigan KA, Bean BS. Crypticity and functional distribution of the membrane associated alpha-L-fucosidase of human sperm. Mol Reprod Dev 2007; 74(6): 758-66.

[16] Abascal I, Skalaban SR, Grimm KM, et al. Alteration of the isoform composition of plasma-membrane-associated rat sperm alpha-L-fucosidase during late epididymal maturation: comparative characterization of the acidic and neutral isoforms. Biochem $\mathrm{J}$ 1998; 333 ( Pt 1): 201-7.

[17] Aviles M, Abascal I, Martinez-Menarguez JA, et al. Immunocytochemical localization and biochemical characterization of a novel plasma membrane-associated, neutral $\mathrm{pH}$ optimum alpha-L-fucosidase from rat testis and epididymal spermatozoa. Biochem J 1996; 318 ( Pt 3): 821-31.

[18] Hancock LW, Raab LS, Aronson NN, Jr. Synthesis and processing of rat sperm-associated alpha-L-fucosidase. Biol Reprod 1993; 48(6): 1228-38.

[19] Intra J, Cenni F, Perotti ME. An alpha-L-fucosidase potentially involved in fertilization is present on Drosophila spermatozoa surface. Mol Reprod Dev 2006; 73(9): 1149-58

[20] Pasini ME, Intra J, Pavesi G. Expression study of an alpha-1fucosidase gene in the Drosophilidae family. Gene 2008; 420(1): 23-33.

[21] Intra J, Cenni F, Pavesi G, Pasini M, Perotti ME. Interspecific analysis of the glycosidases of the sperm plasma membrane in Drosophila. Mol Reprod Dev 2009; 76(1): 85-100.

[22] Matsumoto M, Hirata J, Hirohashi N, Hoshi M. Sperm-egg binding mediated by sperm alpha-L-fucosidase in the ascidian, Halocynthia roretzi. Zoolog Sci 2002; 19(1): 43-8

[23] Focarelli R, Cacace MG, Seraglia R, Rosati F. A nonglycosylated, $68-\mathrm{kDa}$ alpha-L-fucosidase is bound to the mollusc bivalve Unio elongatulus sperm plasma membrane and differs from a glycosylated $56-\mathrm{kDa}$ form present in the seminal fluid. Biochem Biophys Res Commun 1997; 234(1): 54-8.

[24] Srivastava PN, Farooqui AA, Gould KG. Studies on hydrolytic enzymes of chimpanzee semen. Biol Reprod 1981; 25(2): 363-9.

[25] Jauhiainen A, Vanha-Perttula T. alpha-L-Fucosidase in the reproductive organs and seminal plasma of the bull. Biochim Biophys Acta 1986 15; 880(1): 91-5.

[26] Jimenez-Movilla M, Aviles M, Gomez-Torres MJ, et al. Carbohydrate analysis of the zona pellucida and cortical granules of human oocytes by means of ultrastructural cytochemistry. Hum Reprod 2004; 19(8): 1842-55

[27] Flechon JE, Degrouard J, Kopecny V, Pivko J, Pavlok A, Motlik J. The extracellular matrix of porcine mature oocytes: origin, composition and presumptive roles. Reprod Biol Endocrinol 2003; 1: 124 .

[28] Tanghe S, Van Soom A, Duchateau L, De Kruif A. Inhibition of bovine sperm-oocyte fusion by the p-aminophenyl derivative of D-mannose. Mol Reprod Dev 2004; 67(2): 224-32.
[29] Boldt J, Howe AM, Parkerson JB, Gunter LE, Kuehn E. Carbohydrate involvement in sperm-egg fusion in mice. Biol Reprod 1989; 40(4): 887-96.

[30] Miranda PV, Gonzalez-Echeverria F, Marin-Briggiler CI, Brandelli A, Blaquier JA, Tezon JG. Glycosidic residues involved in human sperm-zona pellucida binding in vitro. Mol Hum Reprod 1997; 3(5): 399-404

[31] Mendelson TC. Sexual isolation evolves faster than hybrid inviability in a diverse and sexually dimorphic genus of fish (Percidae: Etheostoma). Evolution Int J Org Evolution 2003; 57(2): 317-27.

[32] Page LM. Handbook of darters. Neptune City, NJ: TFH Publications 1983

[33] Mendelson TC, Imhoff VE, Venditti JJ. The accumulation of reproductive barriers during speciation: postmating barriers in two behaviorally isolated species of darters (Percidae: Etheostoma). Evolution 2007; 61(11): 2596-606.

[34] Howard DJ. Conspecific Sperm and Pollen Precedence and Speciation. Annu Rev Ecol Syst 1999; 30(1): 109-32.

[35] Fuller RC. Sperm competition affects male behaviour and sperm output in the rainbow darter. In: Proceedings of the Royal Society of London, B 1998; Vol. 265(1998): pp. 2365-71.

[36] Winchester B, Barker C, Baines S, Jacob GS, Namgoong SK, Fleet G. Inhibition of alpha-L-fucosidase by derivatives of deoxyfuconojirimycin and deoxymannojirimycin. Biochem J 1990; 265(1): 277-82.

[37] Alhadeff JA. Structure and function of mammalian alpha-Lfucosidases. Trends Comp Biochem Physiol [review] 1998; 4: 10518.

[38] Geiger N. Electron microscopy studies on salmonid spermatozoa Revue Suisse Zool 1955; 62: 325-34.

[39] Mattei X. Spermiogenese Comparee des poissons. In: Baccetti B, Ed. New York: Academic Press 1970.

[40] Jamieson B. Fish evolution and systematics: evidence from spermatozoa. Cambridge: Cambridge University Press 1991.

[41] Quagio-Grassiotto I, Antoneli FN, Oliveira C. Spermiogenesis and sperm ultrastructure in Cichla intermedia with some considerations about Labroidei spermatozoa (Teleostei, Perciformes, Cichlidae) Tissue Cell 2003 ; 35(6): 441-6.

[42] Gusmao-Pompiani P, Oliveira C, Quagio-Grassiotto I. Spermatozoa ultrastructure in Sciaenidae and Polynemidae (Teleostei: Perciformes) with some consideration on Percoidei spermatozoa ultrastructure. Tissue Cell 2005; 37(3): 177-91.

[43] Maricchiolo G, Genovese L, Laura R, Micale V, Muglia U. Fine structure of spermatozoa in the common pandora (Pagellus erythrinus Linnaeus, 1758) (Perciformes, Sparidae). Histol Histopathol 2004; 19(4): 1237-40.

[44] Fishelson L, Delarea Y, Gon O. Testis structure, spermatogenesis, spermatocytogenesis, and sperm structure in cardinal fish (Apogonidae, Perciformes). Anat Embryol (Berl) 2006; 211(1): 31-46.

[45] Intra J, Perotti ME, Pavesi G, Horner D. Comparative and phylogenetic analysis of alpha-L-fucosidase genes. Gene 2007; 392(1-2): 34-46

[46] Kretz KA, Cripe D, Carson GS, Fukushima H, O'Brien JS. Structure and sequence of the human alpha-L-fucosidase gene and pseudogene. Genomics 1992; 12(2): 276-80.

This is an open access article licensed under the terms of the Creative Commons Attribution Non-Commercial License (http: //creativecommons.org/licenses/by-nc/ 3.0/) which permits unrestricted, non-commercial use, distribution and reproduction in any medium, provided the work is properly cited. 